\title{
Interactions of Human Myeloid Cells with Natural Killer Cell Subsets In Vitro and In Vivo
}

\author{
Obinna Chijioke and Christian Münz \\ Department of Viral Immunobiology, Institute of Experimental Immunology, University of Zurich, Winterthurerstrasse 190,8057 \\ Zurich, Switzerland \\ Correspondence should be addressed to Christian Münz, christian.muenz@uzh.ch
}

Received 17 January 2011; Accepted 7 February 2011

Academic Editor: Roberto Biassoni

Copyright (๑) 2011 O. Chijioke and C. Münz. This is an open access article distributed under the Creative Commons Attribution License, which permits unrestricted use, distribution, and reproduction in any medium, provided the original work is properly cited.

In both human and mouse it has been recently realized that natural killer (NK) cells do not emerge from the bone marrow with full functional competence but rather acquire functions in interaction with antigen-presenting cells (APCs), primarily dendritic cells (DCs). Here we review the mechanisms and the consequences of this NK-cell preactivation, as well as discuss new experimental models that now allow investigating these interactions for human NK cells and their response to human pathogens in vivo. These investigations will allow harnessing NK cells during vaccination for improved innate and adaptive immunity.

\section{Introduction}

Myeloid cells and natural killer (NK) cells constitute two types of innate leucocytes that restrict infections early on and then influence adaptive immune responses to pathogen invasion, so that $\mathrm{B}$ and $\mathrm{T}$ cells efficiently clear invading microorganisms. In recent years it has become apparent that myeloid and NK cells perform their tasks not in isolation but influence and activate each other for more efficient innate immunity [1]. Particularly, dendritic cells (DCs), which have long been realized to be essential sentinels to detect infections for priming of adaptive T-cell responses [2], have recently been shown to be crucial for efficient NK-cell responses [3]. The diversity of DC subsets with migratory, secondary lymphoid tissue resident, and inflammatory DCs developing from monocytes [4] allows for a fine-tuned activation of NK cells at different tissue sites. In addition, maturation of these DC subsets upon encounter of different pathogenassociated molecular patterns (PAMPs) equips them with NK-cell stimulatory abilities adjusting to the need of stronger or weaker NK-cell activation in the course of an immune response [5]. These mature DCs migrate or are resident in secondary lymphoid tissues (Figure 1), a major site of NK-cell activation during innate immune responses $[3,6]$.
While in mice NK cells seem to need to home there during immune responses [3, 7], human secondary lymphoid tissues contain substantial amounts of NK cells $[8,9]$. Thus, NKcell activation in secondary lymphoid tissues by mature DCs allows for the activation of innate lymphocytes, which limit pathogen replication prior to priming of adaptive immune responses by the same antigen-presenting cells (APCs) at the same sites.

Once activated, NK cells contribute to the mounting immune response primarily via cytokine production and cytotoxicity. In humans, these two functions can be mediated by different NK-cell differentiation stages with $\mathrm{CD} 56^{\text {bright }} \mathrm{CD} 16^{-} \mathrm{NK}$ cells preferentially producing cytokines upon activation by APCs and terminally differentiated $\mathrm{CD} 56^{\mathrm{dim}} \mathrm{CD} 16^{+} \mathrm{NK}$ cells being potent killers of virus- infected and-transformed cells $[10,11]$. Interestingly, $\mathrm{CD} 56^{\text {bright }} \mathrm{CD} 16^{-} \mathrm{NK}$ cells, which primarily react to activation by mature DCs with cytokine production, with elevation of the cytotoxic ability and with expansion, are enriched in T-cell zones of secondary lymphoid organs $[8,9]$. Thus, human NK-cell distribution seems to be adjusted to ensure efficient activation by DCs to rapidly mobilize the NK-cell compartment during the initial phase of immune responses to infections. 


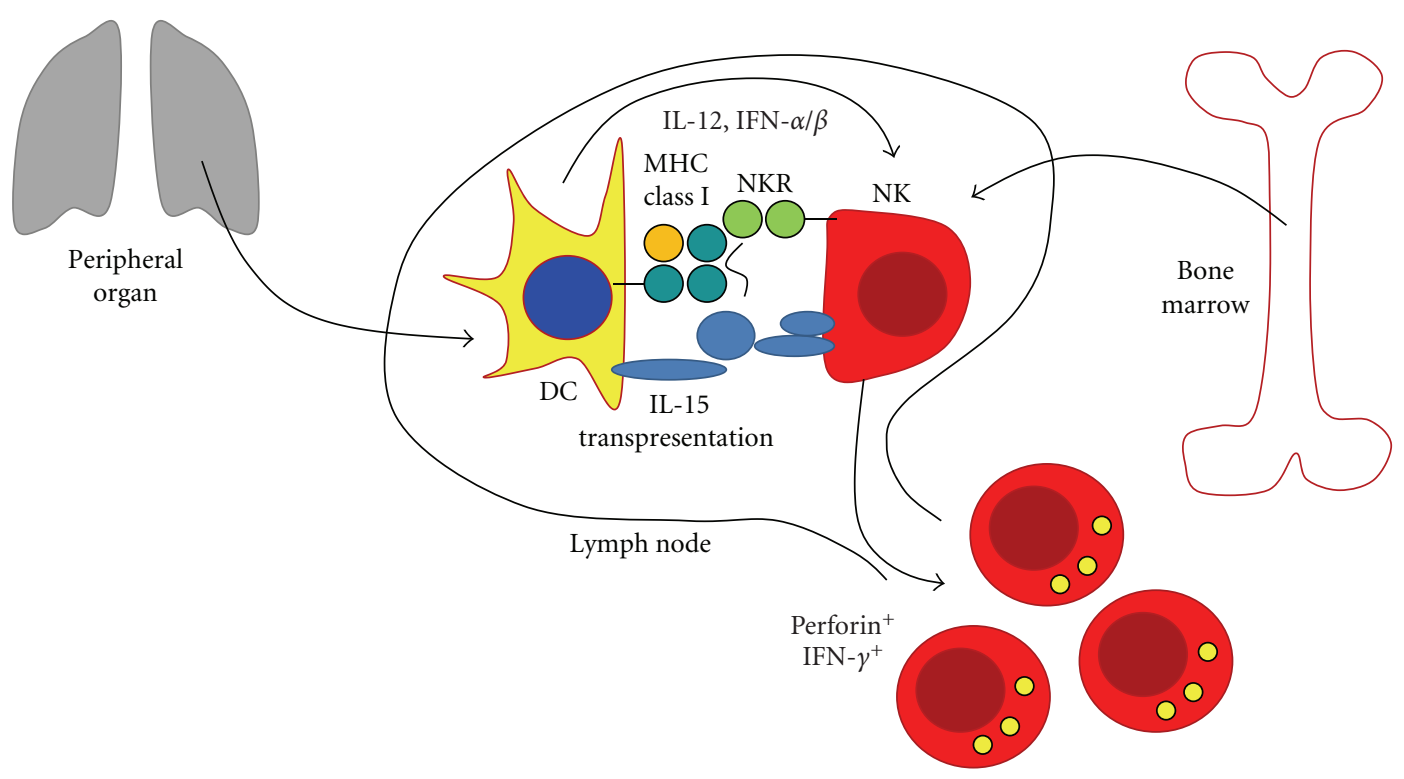

FIGURE 1: NK-cell preactivation in secondary lymphoid organs by dendritic cells (DCs). Mature DCs preactivate NK cells in secondary lymphoid tissues but are not killed in the process and continue to prime adaptive immune responses. They achieve this by simultaneously transmitting IL-15-dependent activating signals via transpresentation of this cytokine in distinct domains of their synapse with DCs, while inhibiting NK-cell lysis by engaging inhibitory receptors via MHC class I molecules occurs in other domains of the synapse center. In addition, DC-derived IL-12 and type I IFN (IFN- $\alpha / \beta)$ increase IFN- $\gamma$ production and cytotoxicity of conjugated NK cells. NK cells home to these sites after development in the bone marrow, while mature DCs migrate there at increased frequency from peripheral tissues after their maturation.

The present paper will summarize recent studies providing information about the molecular interactions that take place between NK cells and myeloid antigen-presenting cells and how these interactions can lead to completely different outcomes for the ensuing immune responses, ranging from immune suppression after APC editing to enhanced Th1polarized immune responses.

\section{NK-Cell Activation by DCs-Synapses and Cytokines}

However, this rapid mobilization of cytotoxic innate effector cells bears the risk of compromising efficient priming of adaptive immune response due to APC killing. Indeed, NK cells in C57BL/6 mice, which carry an activating NK-cell receptor, $\mathrm{Ly} 49 \mathrm{H}$, directly engaging the viral $\mathrm{m} 157$ protein of mouse cytomegalovirus (MCMV), kill MCMV-infected DCs so efficiently that ensuing adaptive immune responses are compromised and have difficulties controlling persistent viral infection [12]. However, in most other instances moderate NK-cell responses can be activated by mature DCs, which then go on to prime protective adaptive immune responses. This is achieved by protecting mature DCs from NK-cell cytotoxicity during NK-cell activation, and the immunological synapse, which mediates these interactions, fulfills both functions. Indeed, two mechanisms have been described by which mature DCs protect themselves from NK-cell cytotoxicity. On the one hand, mature DCs express serpin protease inhibitors, like protease inhibitor 9 (PI9), that inhibit apoptosis inducing proteases, like granzyme B, which are delivered to targets of NK-cell cytotoxicity via perforin pores $[13,14]$. On the other hand, DC maturation upregulates surface expression of major histocompatibility complex (MHC) class I molecules, which serve as ligands of inhibitory receptors on NK cells of the CD94/NKG2 and KIR families (Figure 1). Indeed, blocking of MHC class I molecules restores mature DC killing by NK cells to levels observed with immature DCs [15]. Furthermore, mature DCs rapidly polarize these MHC class I molecules to their synapses with NK cells to ensure inhibition of cytotoxicity [16]. Therefore, mature DCs ensure in their interaction with NK cells that they survive to allow successive priming of adaptive immune responses.

Parallel to these inhibitory interactions, mature DCs, however, activate resting NK cells $[15,17-19]$, and this interaction is crucial for mounting efficient NK-cell responses [3]. DC cytokine secretion or transpresented cytokines play a major role in this NK-cell activation. While IL-12 and IL18 primarily stimulate cytokine production, for example of IFN- $\gamma$, by NK cells $[5,6]$, type I IFN is mainly involved in the augmentation of NK-cell cytotoxicity [20]. In addition, IL-15, presented by IL-15R $\alpha$ on mature DCs [6], can stimulate NK-cell survival, proliferation, and differentiation from $\mathrm{CD} 56^{\text {bright }} \mathrm{CD} 16^{-}$to $\mathrm{CD} 56^{\mathrm{dim}} \mathrm{CD} 16^{+} \mathrm{NK}$ cells $[6,8$, $16,21,22]$. Indeed, IL-15 is crucial for DC-mediated activation of NK cells in mice [3]. Interestingly, these activating interactions, especially IL-15 transpresentation to IL-15R $\beta / \gamma_{c}$, between mature DCs and resting NK cells seem to be mediated through distinct domains in the center of 
the immunological synapse (Figure 1) [16]. These activating domains segregate from inhibitory domains that allow MHC class I/KIR interactions and form rapidly within the first minutes of mature DC interaction with NK cells. The rapid establishment of the immunological synapse between mature DCs and resting NK cells, which ensures NK-cell activation and DC protection from NK-cell cytotoxicity at the same time, seems to be important, because in vivo imaging has revealed that DCs and NK cells might only interact with each other in T-cell areas of secondary lymphoid tissues for short periods of time with the majority of contacts being around $1 \mathrm{~min}[23,24]$. At these early time points, however, the synapse between DCs and NK cells is not stabilized by cytoskeletal components like actin. This occurs similarly to T cells only after $20 \mathrm{~min}$ and might be required to exchange all necessary signals between these two innate leucocyte populations. Especially, IL-12 might only efficiently polarize to the synapse at these late time points, and efficient cytokine production by NK cells might therefore require longer interactions with DCs [25]. This late NK-cell activation might be further modulated by IL-18 released from DCs [26]. Thus, human NK cells, especially those resident in secondary lymphoid tissues, might entertain longer interactions with DCs to reach their full functional potential and might even differentiate into $\mathrm{CD} 56^{\mathrm{dim}} \mathrm{CD} 16^{+} \mathrm{NK}$ cells upon this interaction.

\section{Myeloid Cell Editing by NK Cells-Cytotoxicity and Activation}

While we consider NK cells primarily as effector cells, activated early after sensing of infections by DCs, it is worthwhile to consider the flip side of their interaction with DCs, namely, DC maturation by activated NK cells as well as NK-cell regulation of other myeloid cells. In vitro activated human NK cells can induce phenotypic maturation of DCs via their secretion of IFN- $\gamma$ and TNF- $\alpha$, and these changes are cell-contact dependent $[18,19,27]$. Monocytes have been shown to secrete more TNF- $\alpha$ in the presence of activated NK cells in a process that also was shown to require cellto-cell contact [28], and polymorphonuclear cells increase their phagocytic activity and are more resistant to apoptosis when conditioned with supernatant from cytokine-activated NK cells [29]. Even the differentiation of $\mathrm{CD} 14^{+}$monocytes into DCs with typical functional attributes was reported to be induced by NK cells and was mediated by GM-CSF production and CD154 expression by the CD56 $6^{\text {bright }} \mathrm{NK}$-cell subset [30]. This shaping of the dendritic cell fate extends to the killing of immature DCs by activated autologous NK cells in certain in vitro settings with involvement of CD40CD40L interactions and the activating NK-cell receptors (NCRs) NKp30, NKp46, and DNAM-1, whereas increased expression of MHC class I molecules on matured DCs protects them from NK-cell-mediated cytotoxicity $[15,19$, 31-35]. Degranulation of NK cells, a surrogate for cytotoxic activity, can be observed against human cytomegalovirusinfected DCs, with dominant contributions of NKp46 and DNAM-1 and exerted mainly by CD94/NKG2A ${ }^{+}$NK cells [36], as also reported for the cytotoxicity towards immature
DCs [34]. Human dendritic cells infected with influenza virus increase cytotoxicity of NK cells towards autologous immature DCs but are themselves spared from NK-cellmediated cytolysis, possibly due to upregulation of MHC class I molecules [37]. As for mature DCs, upregulation of MHC class I molecules after treatment with LPS protects human microglial cells-resident macrophages of the central nervous system-from NK-cell cytotoxicity [38]. Nonactivated microglial cells on the other hand are efficiently killed by activated NK cells mediated in part by the activating NCRs NKp46 and DNAM-1 [38]. Conversely to DCs and microglia, high-dose LPS-activated human macrophages are prone to cytolysis mediated by autologous NK cells compared to less activated macrophages [39], and this is also influenced by the polarization status of macrophages [40] as well as the pathway of macrophage activation [41]. This NK-cell cytotoxicity against activated macrophages was reported to be partly dependent on IL-10-induced upregulation of NKG2D ligands [42]. Thus, NK cells can edit myeloid antigenpresenting cells via different mechanisms, and different myeloid cells are differently affected. While low numbers of activated NK cells mature DCs via cytokine secretion, high numbers kill immature DCs, resting microglia, and activated macrophages.

These in vitro defined interactions probably form the basis for the modulation of adaptive immune responses in vivo. Indeed, in the draining lymph nodes of mice, recruitment of NK cells and NK-cell-secreted IFN- $\gamma$ seem to be essential for the establishment of Th1 responses [7]. This NK-cell-assisted Th1 polarization renders immune responses more efficient in the clearance of Leishmania infection [43, 44]. Furthermore, depletion of NK cells leads to altered phenotype and numbers of DCs in lymph nodes $[45,46]$, and this can lead to changes in the capacity to prime T-cell responses [12]. Interestingly, in the early phase of mouse cytomegalovirus infection - a mouse model for persistent viral infections-, infected DCs are killed by activated NK cells, and this culling of antigen-presenting cells diminished both antiviral $\mathrm{CD}^{+}$and $\mathrm{CD} 4^{+}$T-cell responses which led to an inability to clear the virus in the long run [12]. Likewise, NK-cell-mediated elimination of DCs in lymph nodes of transplantation models inhibited alloreactive T-cell priming $[46,47]$. Furthermore, targeting of microglia by NK cells reduced disease severity in experimental autoimmune encephalomyelitis models $[48,49]$ via suppression of detrimental Th17 responses [49]. While, therefore, abundant activated NK cells can edit APCs to inhibit immune responses, lower amounts of activated NK cells can mature APCs and thereby use NK-cell recognition of cells, altered by transformation or infection, to initiate adaptive immune responses even upstream of professional APCs like DCs. Along these lines, NK cells, activated in vivo by tumor cell lines with low levels of inhibitory MHC class I molecules, initiated DC-mediated priming of protective $\mathrm{T}$ cells and adaptive memory generation [50]. In a similar setting, antigenexpressing NK-cell targets induced specific cellular as well as humoral adaptive immune responses, possibly involving increased uptake and antigen presentation by myeloid APCs like DCs [51]. Thus, NK cells can influence adaptive immune 
TABle 1: Distribution and frequencies of NK cells, NK-cell subsets, and myeloid cells in mice with reconstituted human immune system components. Only data from two mouse model systems of human immune system reconstitution are shown. Frequency of NK-cell subsets relates to total NK cells. In vivo administration of human cytokines is reported to lead to up to tenfold increases in targeted cell compartments $[22,52] .{ }^{*}$ Chijioke et al., unpublished.

\begin{tabular}{|c|c|c|}
\hline & huNSG & huRag2 $2^{-/-} \gamma_{c}^{-/-}$ \\
\hline $\mathrm{NK}$ cells $\left(\mathrm{CD} 3^{-} \mathrm{NKp} 46^{+}\right.$or $\left.\mathrm{CD} 3^{-} \mathrm{CD} 56^{+}\right)$ & $\begin{array}{c}\text { Bone marrow: } 0.5-1.5 \%[52,54] \\
\text { Blood: } 1-3 \%[52,54] \\
\text { Spleen: } 1-3 \%[52,54] \\
\text { Thymus: not reported } \\
\text { Lung: } 2-5 \%[52,54] \\
\text { Liver: } 3-4.5 \%[52,54]\end{array}$ & $\begin{array}{c}\text { Bone marrow: }<0.2 \%[22] \\
\text { Blood: }<0.5 \%[22] \\
\text { Spleen: }<0.2 \%[22] \\
\text { Thymus: }<1 \%[22] \\
\text { Lung: not reported } \\
\text { Liver: }<0.4 \%[22]\end{array}$ \\
\hline $\mathrm{CD}^{\text {bright }} \mathrm{CD} 16^{-} \mathrm{NK}$ cells & $\begin{array}{c}\text { Bone marrow: }>30 \%\left[{ }^{*}\right] \\
\text { Blood: } 25 \%\left[{ }^{*}\right] \\
\text { Spleen: } 5-10 \%\left[54,{ }^{*}\right] \\
\text { Thymus: not reported } \\
\text { Liver: } 5 \%\left[{ }^{*}\right]\end{array}$ & $\begin{array}{c}\text { Bone marrow: } 10 \%[22] \\
\text { Blood: not reported } \\
\text { Spleen: } 40 \%[22] \\
\text { Thymus: } 30 \%[22] \\
\text { Liver: not reported }\end{array}$ \\
\hline $\mathrm{CD}^{\mathrm{dim}}{ }^{\mathrm{dim}} \mathrm{CD} 6^{+} \mathrm{NK}$ cells & $\begin{array}{c}\text { Bone marrow: }<15 \%\left[{ }^{*}\right] \\
\text { Blood: } 20 \%\left[{ }^{*}\right] \\
\text { Spleen: } 30-40 \%\left[54,{ }^{*}\right] \\
\text { Thymus: not reported } \\
\text { Liver: } 30 \%\left[{ }^{*}\right] \\
\end{array}$ & $\begin{array}{c}\text { Bone marrow: } 90 \%[22] \\
\text { Blood: not reported } \\
\text { Spleen: } 60 \%[22] \\
\text { Thymus: } 70 \%[22] \\
\text { Liver: not reported } \\
\end{array}$ \\
\hline $\mathrm{CD} 6^{-} \mathrm{NK}$ cells & $\begin{array}{c}\text { Bone marrow: }<10 \%[*] \\
\text { Blood: } 30 \%[*] \\
\text { Spleen: } 30-40 \%\left[54,{ }^{*}\right] \\
\text { Thymus: not reported } \\
\text { Liver: } 40-50 \%\left[{ }^{*}\right]\end{array}$ & $\begin{array}{c}\text { Bone marrow: \% not reported [22] } \\
\text { Blood: not reported } \\
\text { Spleen: \% not reported [22] } \\
\text { Thymus: \% not reported [22] } \\
\text { Liver: not reported } \\
\end{array}$ \\
\hline 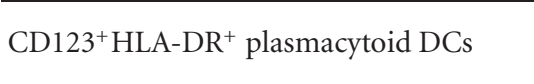 & $\begin{array}{l}\text { Bone marrow: not reported } \\
\text { Spleen: } 1-2 \%[54]\end{array}$ & $\begin{array}{c}\text { Bone marrow: } 1.5-3 \%[22,55] \\
\text { Spleen: }<0.5 \%[55]\end{array}$ \\
\hline $\mathrm{CD}_{11 \mathrm{c}^{+} \text {HLA-DR }}{ }^{+}$myeloid DCs & $\begin{array}{c}\text { Bone marrow: } 1-3 \%[56] \\
\text { Blood: not reported } \\
\text { Spleen: } 1-3 \%[54,56] \\
\end{array}$ & $\begin{array}{c}\text { Bone marrow: } 1-3 \%[22,55] \\
\text { Blood: } 5 \%[57] \\
\text { Spleen: }<2 \%[55]\end{array}$ \\
\hline $\mathrm{CD}_{141^{+} \text {HLR-DR }}^{+}$myeloid DCs & Spleen: $<0,1 \%[58]$ & Not reported \\
\hline $\mathrm{CD}_{3}{ }^{+}$myeloid cells & $\begin{array}{c}\text { Bone marrow: } 5-15 \%[56] \\
\text { Blood: } 5-10 \%[56] \\
\text { Spleen: } 5-10 \%[56]\end{array}$ & $\begin{array}{l}\text { Bone marrow: } 20 \%[57] \\
\text { Blood: not reported } \\
\text { Spleen: not reported }\end{array}$ \\
\hline $\mathrm{CD}_{14}{ }^{+}$monocytes/macrophages & $\begin{array}{c}\text { Bone marrow: } 6-10 \%[52,59] \\
\text { Blood: } 2-5 \%[52,60] \\
\text { Spleen: } 1-3 \%[52,59] \\
\text { Lung: } 10-20 \%[52] \\
\text { Liver: } 5-10 \%[52] \\
\end{array}$ & $\begin{array}{c}\text { Bone marrow: } 2 \% \text { [57] } \\
\text { Blood: } 15 \% \text { [57] } \\
\text { Spleen: not reported } \\
\text { Lung: not reported } \\
\text { Liver: not reported } \\
\end{array}$ \\
\hline $\mathrm{CD} 66^{+}$granulocytes & Not reported & $\begin{array}{c}\text { Bone marrow: } 10 \%[57] \\
\text { Blood: } 5 \%[57]\end{array}$ \\
\hline $\mathrm{CD}_{15} 5^{+}$neutrophils & $\begin{array}{l}\text { Bone marrow: } 4 \%[59] \\
\quad \text { Spleen: } 1 \%[59]\end{array}$ & Not reported \\
\hline
\end{tabular}

*Chijioke et al., unpublished.

responses by at least three mechanisms. They can provide a favorable cytokine milieu for Th1 priming by DCs, they can kill subsets of APCs to edit or even inhibit immune responses, and, finally, they have the capacity to even initiate immune activation after stimulation by somatic cells.

\section{NK-Cell Preactivation and Distribution In Vivo}

The in vitro studies described in the previous paragraph examining the interplay between human NK cells and myeloid cells mostly utilized activated NK cells, mainly activated with cytokines (in most cases IL-2), while nonactivated or resting NK cells had lesser or no regulatory function on the interacting myeloid cells. Equally, in mouse antiviral immune responses in vivo, only activated NK cells, by virtue of binding of the activating $\mathrm{NK}$-cell receptor $\mathrm{Ly} 49 \mathrm{H}$ with the virus-encoded protein $\mathrm{m} 157$ on infected cells, were able to alter antiviral T-cell responses through the killing of DCs but not NK cells lacking the Ly49H receptor [12]. Studies trying to assess the in vivo function of human NK cells using mice with reconstituted human immune system components found that these demonstrated dampened effector functions, 
however, increased to full functional competence of the NKcell compartment after preactivation with IL-15 or poly(I:C) ex vivo [22, 52-54]. IL-15 was able to directly preactivate NK cells, while poly(I:C) required splenic bystander cells to do so, suggesting that TLR3, although expressed by human NK cells, is not able to fully activate human NK cells in vivo [54]. Preactivation of human NK cells also enhanced clearing of transferred MHC class I-deficient tumor cells in vivo $[52,54]$. In addition to preactivation, IL-15, and especially complexes of IL- 15 with IL- $15 \mathrm{R} \alpha$, were able to induce terminal differentiation of human NK cells and significantly expanded these innate lymphocytes in vivo by promoting the development of $\mathrm{CD} 56^{\mathrm{dim}} \mathrm{CD} 16^{+}$cells from their $\mathrm{CD} 56^{\text {bright }} \mathrm{CD} 16^{-}$precursors $[22,52]$. Thus, similar to mice [3], human NK cells require preactivation by IL15 to reach their functional capacity in vivo. However, it is likely that this cytokine is not produced in sufficient amounts by the human hematopoietic cell lineages reconstituting in these in vivo models and therefore hinders reconstitution of similar frequencies of terminally differentiated NK cells as seen in humans.

With respect to the production of IL-15, human myeloid reconstitution and the location of human IL-15 producing cells might be crucial. In this respect, terminal differentiation of human NK cells was suggested to take place in secondary lymphoid organs [61], and it should be important how well these tissues are reconstituted with human myeloid cells, especially macrophages and DCs. An overview of human myeloid and probably myeloid cell-dependent NKcell reconstitution in different organs of mice with reconstituted human immune system components is given in Table 1. While human myeloid cell reconstitution can be observed in peripheral blood and spleen, reaching nearly similar frequencies of human DCs and around one-third of the frequency of human monocytes/macrophages compared to the splenic and peripheral blood populations of these cells in humans, secondary lymphoid organogenesis is compromised in these mice, because of the deficiency in $\gamma_{\mathrm{c}}$-chain expression $[57,58,60]$. Often only the mesenteric lymph node can be macroscopically observed in these mice. Thus, enhanced myeloid reconstitution and measures to promote secondary lymphoid tissue development in these mice could also increase total NK-cell numbers as well as their terminal differentiation. Additional modifications of mice with reconstituted human immune system components along these lines could allow the more faithful modeling of innate immune responses in these in vivo systems of the human immune system.

\section{Conclusions}

Innate lymphocyte activation by DCs has now become an integral function of these APCs in addition to the originally recognized priming of adaptive immunity by these cells [1]. Especially NK cells, which are efficient innate effector cells against tumors and virus-infected cells, are attractive targets of this activation and desirable to be harnessed during vaccination. As discussed above, such recruitment of NK-cell effector functions during immunization would both directly target infected and transformed cells, as well as influence the adaptive immune response to vaccine antigens and to antigenic spreading after NK-cell-mediated killing.

\section{Acknowledgments}

The work in our laboratory is in part supported by the National Cancer Institute of the National Institutes of Health (R01CA108609), the Swiss National Science Foundation (310030_126995), the Sassella Foundation (10/02), the Vontobel Foundation and Cancer Research Switzerland (KFS02652-08-2010).

\section{References}

[1] C. Münz, R. M. Steinman, and S. I. Fujii, "Dendritic cell maturation by innate lymphocytes: coordinated stimulation of innate and adaptive immunity," Journal of Experimental Medicine, vol. 202, no. 2, pp. 203-207, 2005.

[2] R. M. Steinman, "Dendritic cells in vivo: a key target for a new vaccine science," Immunity, vol. 29, no. 3, pp. 319-324, 2008.

[3] M. Lucas, W. Schachterle, K. Oberle, P. Aichele, and A. Diefenbach, "Dendritic cells prime natural killer cells by transpresenting interleukin 15," Immunity, vol. 26, no. 4, pp. 503$517,2007$.

[4] W. R. Heath and F. R. Carbone, "Dendritic cell subsets in primary and secondary T cell responses at body surfaces," Nature Immunology, vol. 10, no. 12, pp. 1237-1244, 2009.

[5] T. Strowig, F. Brilot, F. Arrey et al., "Tonsilar NK cells restrict B cell transformation by the epstein-barr virus via IFN- $\gamma$," PLoS Pathogens, vol. 4, no. 2, article e27, 2008.

[6] G. Ferlazzo, M. Pack, D. Thomas et al., "Distinct roles of IL-12 and IL-15 in human natural killer cell activation by dendritic cells from secondary lymphoid organs," Proceedings of the National Academy of Sciences of the United States of America, vol. 101, no. 47, pp. 16606-16611, 2004.

[7] A. Martín-Fontecha, L. L. Thomsen, S. Brett et al., "Induced recruitment of NK cells to lymph nodes provides IFN- $\gamma$ for T1 priming," Nature Immunology, vol. 5, no. 12, pp. 1260-1265, 2004.

[8] G. Ferlazzo, D. Thomas, S. L. Lin et al., "The abundant NK cells in human secondary lymphoid tissues require activation to express killer cell Ig-like receptors and become cytolytic," Journal of Immunology, vol. 172, no. 3, pp. 1455-1462, 2004.

[9] T. A. Fehniger, M. A. Cooper, G. J. Nuovo et al., "CD56 bright natural killer cells are present in human lymph nodes and are activated by T cell-derived IL-2: a potential new link between adaptive and innate immunity," Blood, vol. 101, no. 8, pp. 3052-3057, 2003.

[10] G. Ferlazzo and C. Münz, "Dendritic cell interactions with NK cells from different tissues," Journal of Clinical Immunology, vol. 29, no. 3, pp. 265-273, 2009.

[11] A. Lünemann, J. D. Lünemann, and C. Münz, "Regulatory NK-cell functions in inflammation and autoimmunity," Molecular Medicine, vol. 15, no. 9-10, pp. 352-358, 2009.

[12] D. M. Andrews, M. J. Estcourt, C. E. Andoniou et al., "Innate immunity defines the capacity of antiviral $\mathrm{T}$ cells to limit persistent infection," Journal of Experimental Medicine, vol. 207, no. 6, pp. 1333-1343, 2010.

[13] C. E. Hirst, M. S. Buzza, C. H. Bird et al., "The intracellular granzyme B inhibitor, proteinase inhibitor 9 , is up-regulated 
during accessory cell maturation and effector cell degranulation, and its overexpression enhances CTL potency," Journal of Immunology, vol. 170, no. 2, pp. 805-815, 2003.

[14] J. P. Medema, D. H. Schuurhuis, D. Rea et al., "Expression of the serpin serine protease inhibitor 6 protects dendritic cells from cytotoxic T lymphocyte-induced apoptosis: differential modulation by T helper type 1 and type 2 cells," Journal of Experimental Medicine, vol. 194, no. 5, pp. 657-667, 2001.

[15] G. Ferlazzo, M. L. Tsang, L. Moretta, G. Melioli, R. M. Steinman, and C. Münz, "Human dendritic cells activate resting natural killer $(\mathrm{NK})$ cells and are recognized via the NKp30 receptor by activated NK cells," Journal of Experimental Medicine, vol. 195, no. 3, pp. 343-351, 2002.

[16] F. Brilot, T. Strowig, S. M. Roberts, F. Arrey, and C. Münz, "NK cell survival mediated through the regulatory synapse with human DCs requires IL-15R $\alpha$," Journal of Clinical Investigation, vol. 117, no. 11, pp. 3316-3329, 2007.

[17] N. C. Fernandez, A. Lozier, C. Flament et al., "Dendritic cells directly trigger NK cell functions: cross-talk relevant in innate anti-tumor immune responses in vivo," Nature Medicine, vol. 5, no. 4, pp. 405-411, 1999.

[18] F. Gerosa, B. Baldani-Guerra, C. Nisii, V. Marchesini, G. Carra, and G. Trinchieri, "Reciprocal activating interaction between natural killer cells and dendritic cells," Journal of Experimental Medicine, vol. 195, no. 3, pp. 327-333, 2002.

[19] D. Piccioli, S. Sbrana, E. Melandri, and N. M. Valiante, "Contact-dependent stimulation and inhibition of dendritic cells by natural killer cells," Journal of Experimental Medicine, vol. 195, no. 3, pp. 335-341, 2002.

[20] F. Gerosa, A. Gobbi, P. Zorzi et al., "The reciprocal interaction of NK cells with plasmacytoid or myeloid dendritic cells profoundly affects innate resistance functions," Journal of Immunology, vol. 174, no. 2, pp. 727-734, 2005.

[21] C. Münz, T. Dao, G. Ferlazzo, M. A. De Cos, K. Goodman, and J. W. Young, "Mature myeloid dendritic cell subsets have distinct roles for activation and viability of circulating human natural killer cells," Blood, vol. 105, no. 1, pp. 266-273, 2005.

[22] N. D. Huntington, N. Legrand, N. L. Alves et al., "IL-15 trans-presentation promotes human NK cell development and differentiation in vivo," Journal of Experimental Medicine, vol. 206, no. 1, pp. 25-34, 2009.

[23] K. R. Garrod, S. H. Wei, I. Parker, and M. D. Cahalan, "Natural killer cells actively patrol peripheral lymph nodes forming stable conjugates to eliminate MHC-mismatched targets," Proceedings of the National Academy of Sciences of the United States of America, vol. 104, no. 29, pp. 12081-12086, 2007.

[24] H. Beuneu, J. Deguine, B. Breart, O. Mandelboim, J. P. Di Santo, and P. Bousso, "Dynamic behavior of NK cells during activation in lymph nodes," Blood, vol. 114, no. 15, pp. 32273234, 2009.

[25] C. Borg, A. Jalil, D. Laderach et al., "NK cell activation by dendritic cells (DCs) requires the formation of a synapse leading to IL-12 polarization in DCs," Blood, vol. 104, no. 10, pp. 3267-3275, 2004.

[26] C. Semino, G. Angelini, A. Poggi, and A. Rubartelli, "NK/iDC interaction results in IL-18 secretion by DCs at the synaptic cleft followed by NK cell activation and release of the DC maturation factor HMGB1," Blood, vol. 106, no. 2, pp. 609616, 2005.

[27] M. Vitale, M. Della Chiesa, S. Carlomagno et al., "NKdependent DC maturation is mediated by TNF $\alpha$ and IFN $\gamma$ released upon engagement of the NKp30 triggering receptor," Blood, vol. 106, no. 2, pp. 566-571, 2005.
[28] N. Dalbeth, R. Gundle, R. J. O. Davies, Y. C. G. Lee, A. J. McMichael, and M. F. C. Callan, "CD56 bright NK cells are enriched at inflammatory sites and can engage with monocytes in a reciprocal program of activation," Journal of Immunology, vol. 173, no. 10, pp. 6418-6426, 2004.

[29] N. Bhatnagar, H. S. Hong, J. K. Krishnaswamy et al., "Cytokine-activated NK cells inhibit PMN apoptosis and preserve their functional capacity," Blood, vol. 116, no. 8, pp. 1308-1316, 2010.

[30] A. L. Zhang, P. Colmenero, U. Purath et al., "Natural killer cells trigger differentiation of monocytes into dendritic cells," Blood, vol. 110, no. 7, pp. 2484-2493, 2007.

[31] J. L. Wilson, L. C. Heffler, J. Charo, A. Scheynius, M. T. Bejarano, and H. G. Ljunggren, "Targeting of human dendritic cells by autologous NK cells," Journal of Immunology, vol. 163, no. 12, pp. 6365-6370, 1999.

[32] E. Carbone, G. Terrazzano, G. Ruggiero et al., "Recognition of autologous dendritic cells by human NK cells," European Journal of Immunology, vol. 29, no. 12, pp. 4022-4029, 1999.

[33] G. M. Spaggiari, R. Carosio, D. Pende et al., "NK cell-mediated lysis of autologous antigen-presenting cells is triggered by the engagement of the phosphatidylinositol 3-kinase upon ligation of the natural cytotoxicity receptors NKp30 and NKp46," European Journal of Immunology, vol. 31, no. 6, pp. 1656-1665, 2001.

[34] M. D. Chiesa, M. Vitale, S. Carlomagno, G. Ferlazzo, L. Moretta, and A. Moretta, "The natural killer cell-mediated killing of autologous dendritic cells is confined to a cell subset expressing CD94/NKG2A, but lacking inhibitory killer Ig-like receptors," European Journal of Immunology, vol. 33, no. 6, pp. 1657-1666, 2003.

[35] D. Pende, R. Castriconi, P. Romagnani et al., "Expression of the DNAM-1 ligands, Nectin-2 (CD112) and poliovirus receptor (CD155), on dendritic cells: relevance for natural killer-dendritic cell interaction," Blood, vol. 107, no. 5, pp. 2030-2036, 2006.

[36] G. Magri, A. Muntasell, N. Romo et al., "NKp46 and DNAM1 NK-cell receptors drive the response to human cytomegalovirus-infected myeloid dendritic cells overcoming viral immune evasion strategies ," Blood, vol. 117, no. 3, pp. 848856, 2011.

[37] M. Draghi, A. Pashine, B. Sanjanwala et al., "NKp46 and NKG2D recognition of infected dendritic cells is necessary for NK cell activation in the human response to influenza infection," Journal of Immunology, vol. 178, no. 5, pp. 26882698, 2007.

[38] A. Lünemann, J. D. Lünemann, S. Roberts et al., "Human NK cells kill resting but not activated microglia via NKG2D- and NKp46-mediated recognition," Journal of Immunology, vol. 181, no. 9, pp. 6170-6177, 2008.

[39] S. Nedvetzki, S. Sowinski, R. A. Eagle et al., "Reciprocal regulation of human natural killer cells and macrophages associated with distinct immune synapses," Blood, vol. 109, no. 9, pp. 3776-3785, 2007.

[40] F. Bellora, R. Castriconi, A. Dondero et al., "The interaction of human natural killer cells with either unpolarized or polarized macrophages results in different functional outcomes," Proceedings of the National Academy of Sciences of the United States of America, vol. 107, no. 50, pp. 21659-21664, 2010.

[41] P. Eissmann, J. H. Evans, M. Mehrabi, E. L. Rose, S. Nedvetzki, and D. M. Davis, "Multiple mechanisms downstream of TLR4 stimulation allow expression of NKG2D ligands to facilitate macrophage/NK cell crosstalk," Journal of Immunology, vol. 184, no. 12, pp. 6901-6909, 2010. 
[42] U. Schulz, M. Kreutz, G. Multhoff et al., "Interleukin-10 promotes NK cell killing of autologous macrophages by stimulating expression of NKG2D ligands," Scandinavian Journal of Immunology, vol. 72, no. 4, pp. 319-331, 2010.

[43] M. Bajénoff, B. Breart, A. Y. C. Huang et al., "Natural killer cell behavior in lymph nodes revealed by static and real-time imaging," Journal of Experimental Medicine, vol. 203, no. 3, pp. 619-631, 2006.

[44] Y. Laouar, F. S. Sutterwala, L. Gorelik, and R. A. Flavell, "Transforming growth factor- $\beta$ controls $\mathrm{T}$ helper type 1 cell development through regulation of natural killer cell interferon- $\gamma$," Nature Immunology, vol. 6, no. 6, pp. 600-607, 2005.

[45] R. Winkler-Pickett, H. A. Young, J. M. Cherry et al., "In vivo regulation of experimental autoimmune encephalomyelitis by NK cells: alteration of primary adaptive responses," Journal of Immunology, vol. 180, no. 7, pp. 4495-4506, 2008.

[46] S. Laffont, C. Seillet, J. Ortaldo, J. D. Coudert, and J.-C. Guéry, "Natural killer cells recruited into lymph nodes inhibit alloreactive T-cell activation through perforin-mediated killing of donor allogeneic dendritic cells," Blood, vol. 112, no. 3, pp. 661-671, 2008.

[47] G. Yu, X. Xu, D. V. Minh, E. D. Kilpatrick, and C. L. Xian, "NK cells promote transplant tolerance by killing donor antigenpresenting cells," Journal of Experimental Medicine, vol. 203, no. 8, pp. 1851-1858, 2006.

[48] J. W. Leavenworth, C. Schellack, H. J. Kim, L. Lu, P. Spee, and H. Cantor, "Analysis of the cellular mechanism underlying inhibition of EAE after treatment with anti-NKG2A F(ab')," Proceedings of the National Academy of Sciences of the United States of America, vol. 107, no. 6, pp. 2562-2567, 2010.

[49] J. Hao, R. Liu, W. Piao et al., "Central nervous system (CNS)resident natural killer cells suppress Th17 responses and CNS autoimmune pathology," Journal of Experimental Medicine, vol. 207, no. 9, pp. 1907-1921, 2010.

[50] R. Mocikat, H. Braumüller, A. Gumy et al., "Natural killer cells activated by MHC class $\mathrm{I}^{\text {low }}$ targets prime dendritic cells to induce protective CD8 T cell responses," Immunity, vol. 19, no. 4, pp. 561-569, 2003.

[51] P. Krebs, M. J. Barnes, K. Lampe et al., "NK cell-mediated killing of target cells triggers robust antigen-specific $\mathrm{T}$ cellmediated and humoral responses," Blood, vol. 113, no. 26, pp. 6593-6602, 2009.

[52] Q. Chen, M. Khoury, and J. Chen, "Expression of human cytokines dramatically improves reconstitution of specific human-blood lineage cells in humanized mice," Proceedings of the National Academy of Sciences of the United States of America, vol. 106, no. 51, pp. 21783-21788, 2009.

[53] M. C. André, A. Erbacher, C. Gille et al., "Long-term human $\mathrm{CD} 4^{+}$stem cell-engrafted nonobese diabetic/SCID/IL$2 \mathrm{R} \gamma^{\text {null }}$ mice show impaired $\mathrm{CD}^{+} \mathrm{T}$ cell maintenance and a functional arrest of immature NK cells," Journal of Immunology, vol. 185, no. 5, pp. 2710-2720, 2010.

[54] T. Strowig, O. Chijioke, P. Carrega et al., "Human NK cells of mice with reconstituted human immune system components require preactivation to acquire functional competence," Blood, vol. 116, no. 20, pp. 4158-4167, 2010.

[55] E. Traggiai, L. Chicha, L. Mazzucchelli et al., "Development of a human adaptive immune system in cord blood celltransplanted mice," Science, vol. 304, no. 5667, pp. 104-107, 2004.

[56] F. Ishikawa, M. Yasukawa, B. Lyons et al., "Development of functional human blood and immune systems in
NOD/SCID/IL2 receptor $\gamma$ chain $^{\text {null }}$ mice," Blood, vol. 106, no. 5, pp. 1565-1573, 2005.

[57] J. Song, T. Willinger, A. Rongvaux et al., "A mouse model for the human pathogen salmonella typhi," Cell Host and Microbe, vol. 8, no. 4, pp. 369-376, 2010.

[58] L. F. Poulin, M. Salio, E. Griessinger et al., "Characterization of human DNGR-1 $1^{+} \mathrm{BDCA}^{+}$leukocytes as putative equivalents of mouse $\mathrm{CD} 8 \alpha^{+}$dendritic cells," Journal of Experimental Medicine, vol. 207, no. 6, pp. 1261-1271, 2010.

[59] J. Unsinger, J. S. McDonough, L. D. Shultz, T. A. Ferguson, and R. S. Hotchkiss, "Sepsis-induced human lymphocyte apoptosis and cytokine production in "humanized" mice," Journal of Leukocyte Biology, vol. 86, no. 2, pp. 219-227, 2009.

[60] T. Strowig, C. Gurer, A. Ploss et al., "Priming of protective $\mathrm{T}$ cell responses against virus-induced tumors in mice with human immune system components," Journal of Experimental Medicine, vol. 206, no. 6, pp. 1423-1434, 2009.

[61] C. Romagnani, K. Juelke, M. Falco et al., "CD56 ${ }^{\text {bright }} \mathrm{CD} 16^{-}$ killer Ig-like receptor NK cells display longer telomeres and acquire features of CD56 $6^{\mathrm{dim}} \mathrm{NK}$ cells upon activation," Journal of Immunology, vol. 178, no. 8, pp. 4947-4955, 2007. 


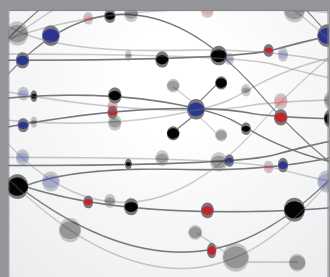

The Scientific World Journal
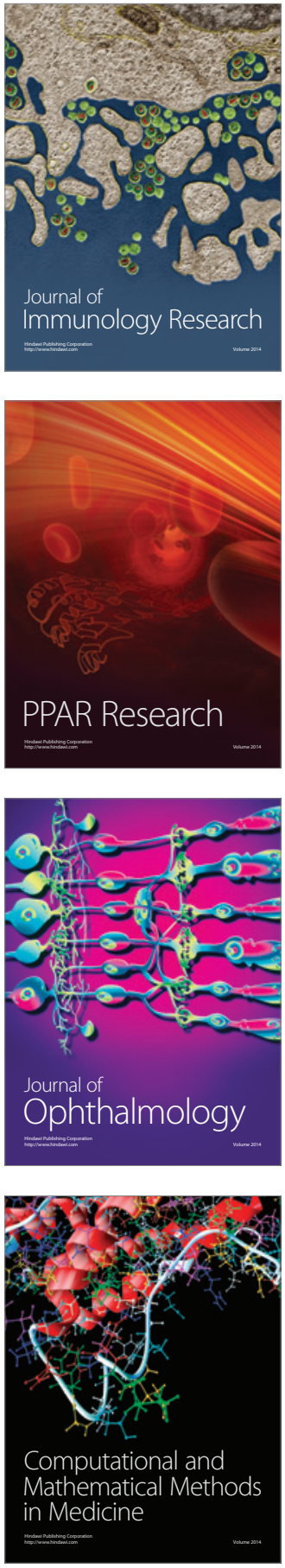

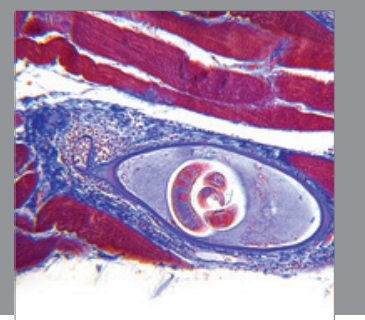

Gastroenterology

Research and Practice
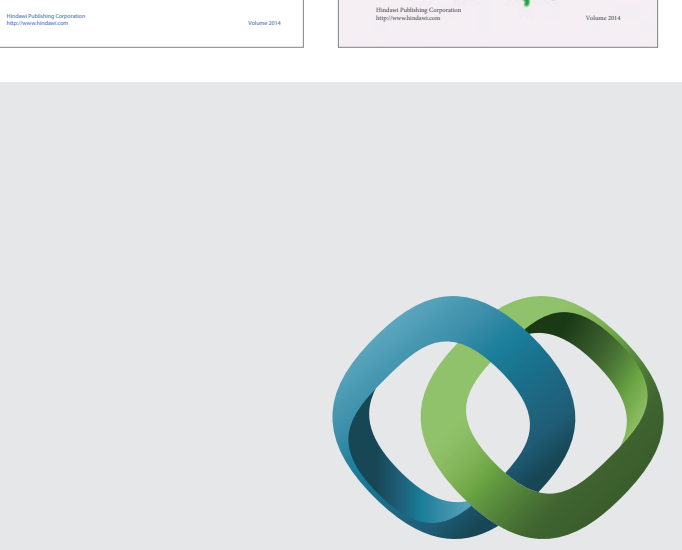

\section{Hindawi}

Submit your manuscripts at

http://www.hindawi.com
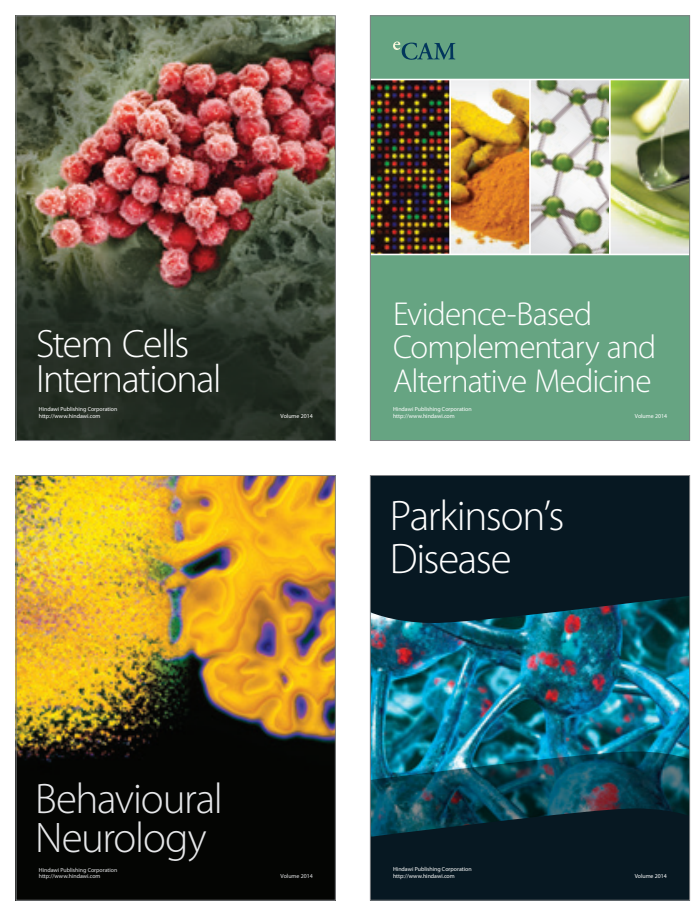

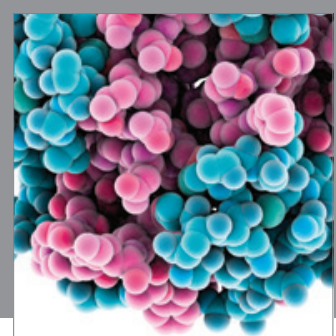

Journal of
Diabetes Research

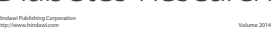

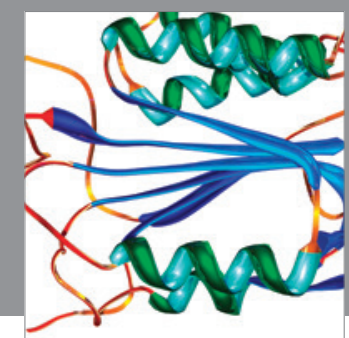

Disease Markers
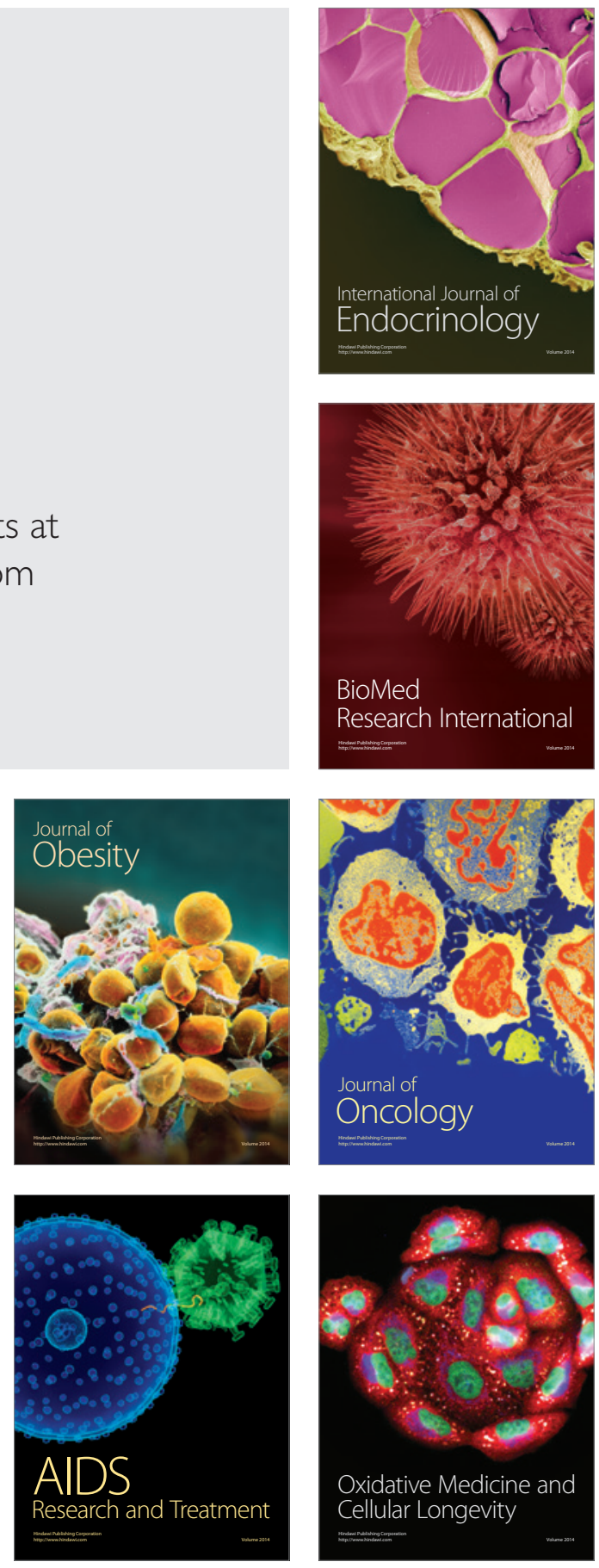